\title{
HIGH-EFFICIENCY P-I-N MICROCRYSTALLINE AND MICROMORPH THIN FILM SILICON SOLAR CELLS DEPOSITED ON LPCVD ZNO COATED GLASS SUBSTRATES
}

\author{
J. Bailat, D. Dominé, R. Schlüchter, J. Steinhauser, S. Faÿ, F. Freitas, C. Bücher, L. Feitknecht, X. Niquille, T. Tscharner, \\ A. Shah, C. Ballif \\ Institut de Microtechnique, University of Neuchâtel, Breguet 2, $\mathrm{CH}-2000$ Neuchâtel, Switzerland \\ Contact author: julien.bailat@unine.ch, tel: (+)41327183344; fax: (+)41327183201
}

\begin{abstract}
The authors report on the fabrication of microcrystalline silicon $p$-i-n solar cells with efficiencies close to $10 \%$, using glass coated with zinc oxide $(\mathrm{ZnO})$ deposited by low pressure chemical vapor deposition (LPCVD).

LPCVD front contacts were optimized for $p$-i-n microcrystalline silicon solar cells by decreasing the free carrier absorption of the layers and increasing the surface roughness. These modifications resulted in an increased current density of the solar cell but also in significantly reduced fillfactor (FF) and open-circuit voltage $\left(V_{o c}\right)$. In order to avoid these reductions, a new surface treatment of the $\mathrm{ZnO}$ is introduced. It transforms profoundly the surface morphology by turning the typical V-shaped valleys of the LPCVD $\mathrm{ZnO}$ into U-shaped valleys and by erasing from the surface small-sized pyramids and asperities. As a result, for fixed deposition parameters, the p-i-n microcrystalline silicon solar cell efficiency increased from $3.3 \%$ to $9.2 \%$

Further optimization of the microcrystalline silicon solar cell on this 'new' type of LPCVD ZnO front contact has led to an efficiency of $9.9 \%$.
\end{abstract}

\section{INTRODUCTION}

Low pressure chemical vapor deposition (LPCVD) zinc oxide $(\mathrm{ZnO})$ is used successfully in amorphous (a$\mathrm{Si}: \mathrm{H})$ and micromorph tandem solar cells as a front transparent conductive oxide (TCO). a-Si:H solar cells have, indeed, reached independently confirmed stable efficiency ( $\eta$ of $9.47 \%$ and micromorph tandem stable efficiencies of $10.8 \%$ [1]. The former result represents one of the highest stable efficiencies ever reported for a-Si:H solar cells.

Such a successful use of LPCVD ZnO has so far not been extended to microcrystalline silicon single junction solar cells ( $\mu \mathrm{c}-\mathrm{Si}: \mathrm{H})$; indeed, up to very recently, the best $\mathrm{p}$-i-n cells on LPCVD ZnO, only attained efficiencies slightly over $8 \%$, whereas on sputtered and etched $\mathrm{ZnO}$, several groups manage to produce on a day-to-day basis cells achieving efficiencies well over $9 \%[2,3]$. Such high efficiencies for $\mu \mathrm{c}-\mathrm{Si}: \mathrm{H}$ approach the "tipping point", beyond which cost-effective manufacture of single junction $\mu c-S i: H$ modules becomes possible. The Jülich group recently reported an efficiency of $8.1 \%$ for a single junction microcrystalline mini-module [4].
The present contribution addresses the issue of fabricating single junction $\mu \mathrm{c}-\mathrm{Si}: \mathrm{H}$ solar cells with efficiencies higher than 9\%, on LPCVD ZnO. In order to reach this goal, the front TCO used previously at IMT within amorphous and micromorph solar cells had to be modified for use within single junction $\mu \mathrm{c}-\mathrm{Si}$ :H solar cells. The modifications were threefold:

1. Reduction of the free carrier absorption (FCA)

2. Increase of the light-trapping capability for long wavelengths $(700-1000 \mathrm{~nm})$

3. Adaptation of the morphology to the growth of $\mu \mathrm{c}-\mathrm{Si}: \mathrm{H}$ material

The first two modifications to our standard front TCO optimized for amorphous silicon solar cells were motivated by the wider absorption spectrum of $\mu \mathrm{c}-\mathrm{Si}: \mathrm{H}$ as compared to a-Si:H. Furthermore, both these modifications were relatively easy to implement technologically: (a) by lowering the doping concentration of the LPCVD ZnO film, so as to reduce FCA; (b) by increasing the film thickness so as to increase the surface roughness and thereby improve light trapping at long wavelengths. As both modifications affect the sheet resistance of the TCO layer in opposing ways, it was possible to keep the latter below $10 \Omega /$ [5].

After carrying out these modifications it was, however, no more possible to obtain high values of opencircuit voltage $\left(\mathrm{V}_{\mathrm{oc}}\right)$ and fill-factor $(\mathrm{FF})$ [6]. The reason invoked was the high roughness and inappropriate surface morphology of the front TCO layer. The third modification to our standard TCO was thus an adaptation of surface morphology to the growth of $\mu \mathrm{c}-\mathrm{Si} \mathrm{H}$. This last task was the most challenging one. On the one hand, the optimal morphology for the growth of $\mu \mathrm{C}-\mathrm{Si}: \mathrm{H}$ cells is not yet known. On the other hand, the process must be simple enough to allow future mass-produced modules to remain cost effective. We present here a novel surface treatment that could fulfill the cost-effectiveness criterion; the treatment renders the surface morphology of LPCVD $\mathrm{ZnO}$ fully adapted to subsequent growth of $\mu \mathrm{c}-\mathrm{Si}: \mathrm{H}$ solar cells. The time used for the surface treatment was varied from 0 to 140'; the efficiency of the $\mu \mathrm{c}-\mathrm{Si}: \mathrm{H}$ solar cells subsequently grown on these substrates, increased from 3.3 to $9.2 \%$ after 40 ' of surface treatment. This surprising effect is described here in detail. Further optimization of the solar cell deposition parameters led us to solar cells with conversion efficiencies as high as $9.9 \%$. 


\section{EXPERIMENTAL}

$\mathrm{ZnO}$ is deposited by LP-CVD, from a vapor-gas mixture of water, diethyl-zinc and diborane, on AF45 glass substrates by Schott. The sheet resistance of the resulting front TCO layers is below $10 \Omega /$.

$\mu \mathrm{c}-\mathrm{Si} \mathrm{H}$ solar cells are deposited by very-high frequency (VHF) plasma enhanced chemical vapor deposition (PECVD) on the front TCO, from a gas phase mixture of silane and hydrogen. The thickness of the $\mu \mathrm{c}-\mathrm{Si}: \mathrm{H}$ intrinsic layer is approximately $1.8 \mu \mathrm{m}$. The back contact consists of $\mathrm{ZnO}$ deposited by LPCVD and a dielectric reflector.

The fully patterned cells have an area of approximately $20 \mathrm{~mm}^{2}$.

The short-circuit current density is calculated from the measurement of the external quantum efficiency (EQE) curve, by integrating, over the wavelength range from 350 to $1000 \mathrm{~nm}$, the product of EQE times the incoming spectral density of photon flux of the solar spectrum.

The current density-voltage (IV) curves are measured under a WACOM solar simulator in standard test conditions $\left(25^{\circ} \mathrm{C}, \mathrm{AM} 1.5 \mathrm{~g}\right.$ spectrum) and calibrated with the short-circuit current-densities obtained from the EQE measurements.

\section{RESULTS}

\section{Changes in surface morphology}

In Fig.1 we represent the three different surface morphologies obtained: a) standard LPCVD ZnO optimized for a-Si:H cells, b) new LPCVD ZnO optimized for $\mu \mathrm{c}-\mathrm{Si}: \mathrm{H}$ before surface treatment and c) the latter, after surface treatment of 80 '.

The surface features of the new front $\mathrm{ZnO}$ layer, optimized for $\mu \mathrm{c}-\mathrm{Si}: \mathrm{H}$ solar cells, are typically two times larger than those of the $\mathrm{ZnO}$ layer optimized for a-Si:H cells. At the same time, the root-mean square roughness ( $\sigma_{\mathrm{RMs}}$ ) also increases from approximately $60 \mathrm{~nm}$ to $200 \mathrm{~nm}$. Both of these facts improve the light scattering for longer wavelengths, i.e. for the range between $700 \mathrm{~nm}$ and $1000 \mathrm{~nm}$, for which $\mu \mathrm{c}-\mathrm{Si}: \mathrm{H}$ has a low absorption coefficient. The absorption length (defined as the inverse of the absorption coefficient) is indeed approximately $2 \mu \mathrm{m}$ and $100 \mu \mathrm{m}$ at these 2 wavelengths, respectively.

The surface of the LP-CVD ZnO layers used as front contact is typically constituted of pyramids of different sizes, irregularly packed on the surface (see Fig.1, a) and b)). These pyramids have flat sides and sharp edges. Between large pyramids, smaller pyramids can be observed as well as asperities.

The surface treatment profoundly changes the morphology (see Fig.1, c)). The smaller pyramids or asperities lying between the larger pyramids completely disappear. The surface becomes slightly smoother with a decrease of $\sigma_{\text {RMs }}$ from approximately $200 \mathrm{~nm}$ without treatment to $175 \mathrm{~nm}$ and $150 \mathrm{~nm}$ after surface treatments of $40^{\prime}$ and 80 ' duration, respectively. The sharp edges of the larger pyramids remain visible after the treatment, forming a network of salient and curved lines at the surface of the front TCO. On the other hand, the sides of the pyramids that are initially flat appeared to have been hollowed by the treatment. This is the reason why the $\mathrm{V}$-shaped valleys seen in Fig1. b) turn into U-shaped valleys in Fig. c).

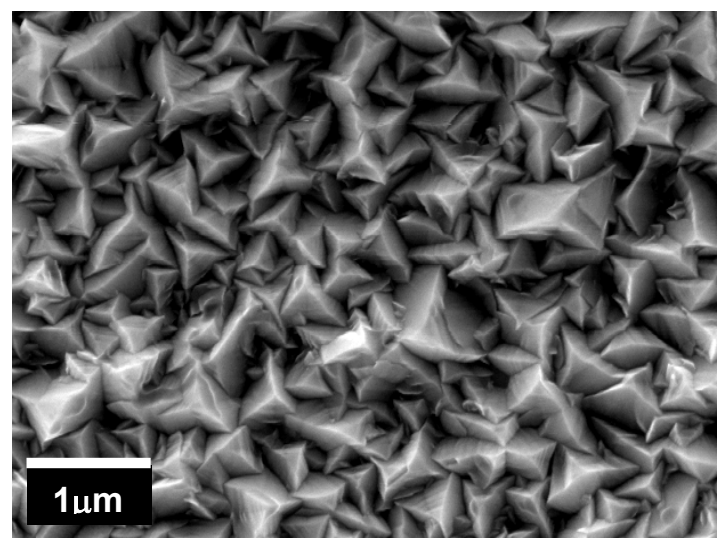

a)

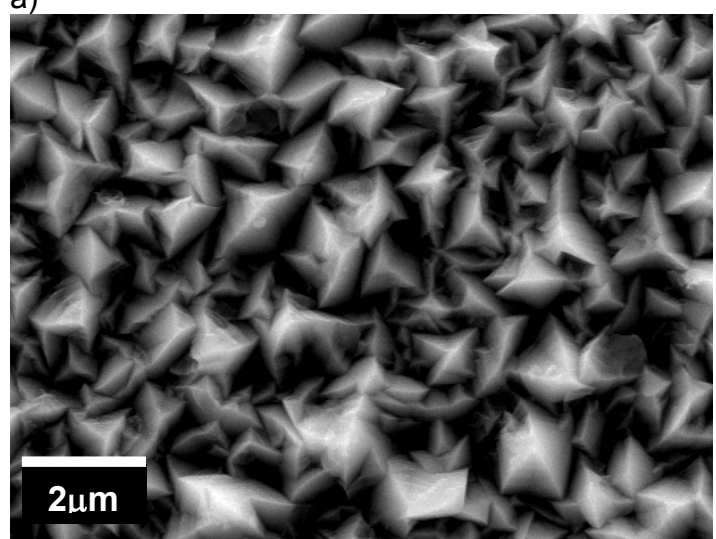

b)

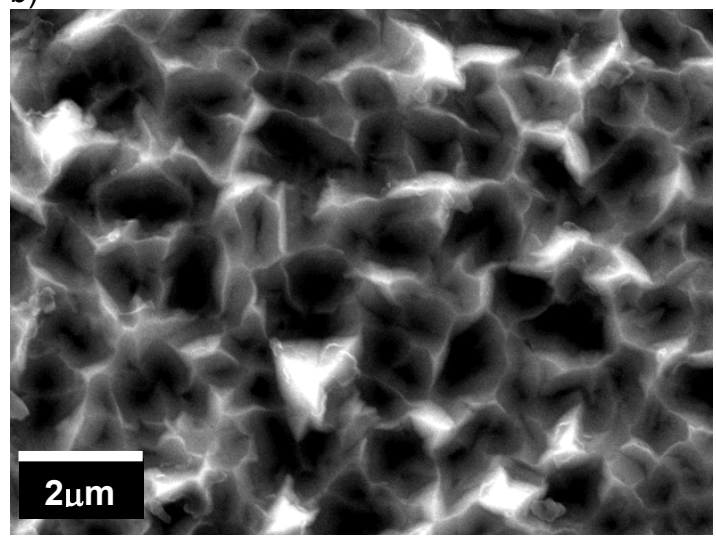

c)

Fig. 1. SEM micrographs of the different surface morphologies of a), the standard front LPCVD ZnO optimized for amorphous cells, b) and c) the new LPCVD ZnO optimized for $\mu \mathrm{c}-\mathrm{Si}: \mathrm{H}$ cells, before and after $80^{\prime}$ of surface treatment, respectively. The surface features of b) are much larger than that of a). The surface treatment changes the morphology of $b$ ), constituted of pyramids of 
different sizes with $\mathrm{V}$-shaped valleys, into a network of Ushaped valleys, in c).

\section{Evolution of the electrical characteristics}

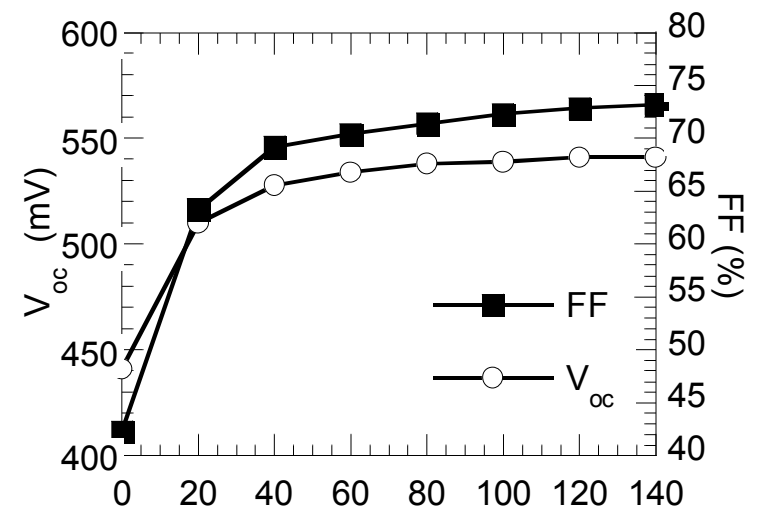

a) Surface treatment time ( $\mathrm{min})$

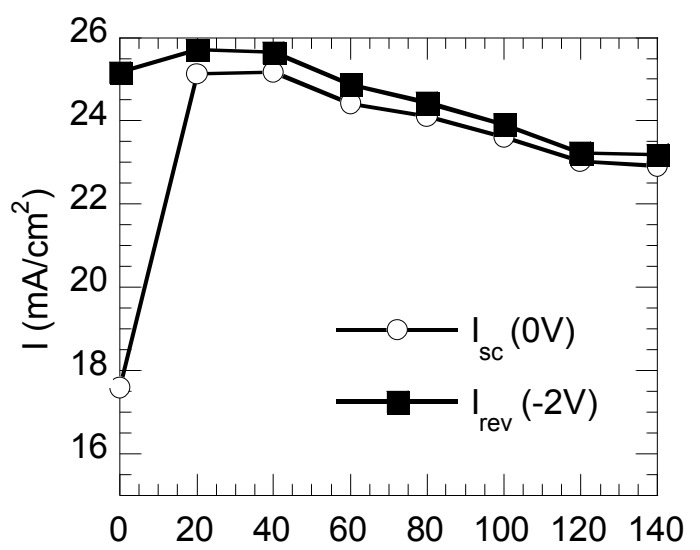

b) Surface treatment time ( $\mathrm{min})$

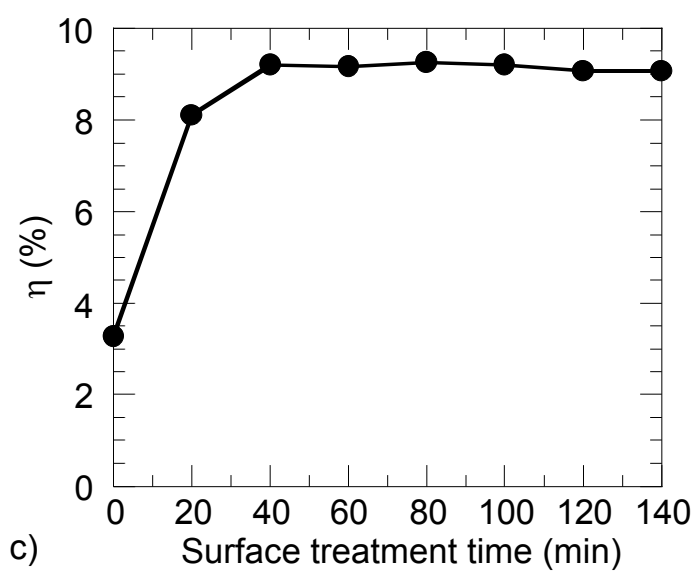

Fig. 2. Evolution of the electrical characteristics of the solar cells as a function of the duration of the surface treatment ( 0 minute stands for no surface treatment): a) $V_{o c}$ and $F F, b) I_{s c}$ and reverse current-density $\left(I_{\text {rev }}\right)$ measured at $-2 \mathrm{~V}, \mathrm{c}) \eta$.

In Fig. 2, the evolution of the main electrical characteristics of the solar cells is represented with respect to the surface treatment time of the front TCO used as substrate.
Already for treatment times of 20 minutes, all the electrical parameters of the solar cells dramatically improve. Longer treatment times keep improving $\mathrm{V}_{\mathrm{oc}}$ and FF, however, $\mathrm{I}_{\mathrm{sc}}$ monotonously decreases. The net result is that for surface treatment times between 60 and 140 minutes $\eta$ remains almost constant at $9.2 \%$.

The current density measured with a reverse bias of $2 \mathrm{~V}, \mathrm{I}_{\text {rev }}$, is used here to evaluate the maximum photocurrent generated by the solar cell. The comparison of the values of $I_{s c}$ and $I_{\text {rev }}$ for a given surface treatment time can be used to evaluate the carrier collection of the cell. The discrepancy of the values with and without surface treatment shows that untreated $\mathrm{ZnO}$ layers are associated with poor carrier collection. Carrier collection immediately improves with 20 minutes of surface treatment.

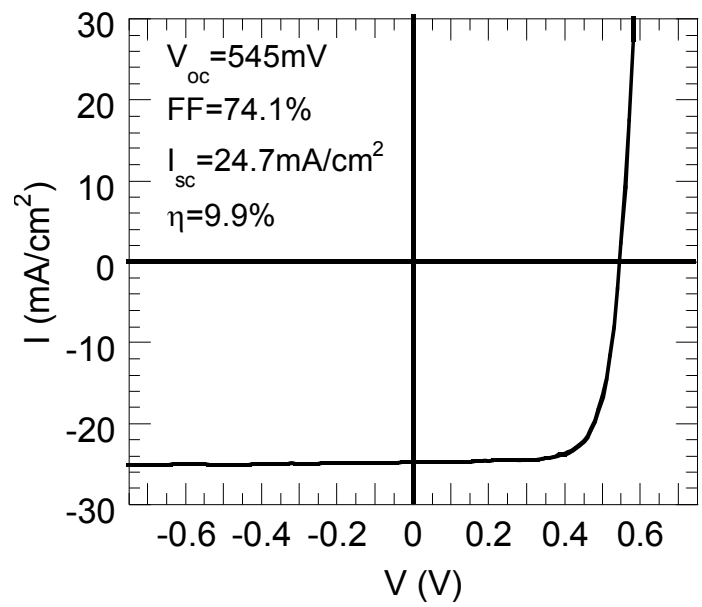

a)

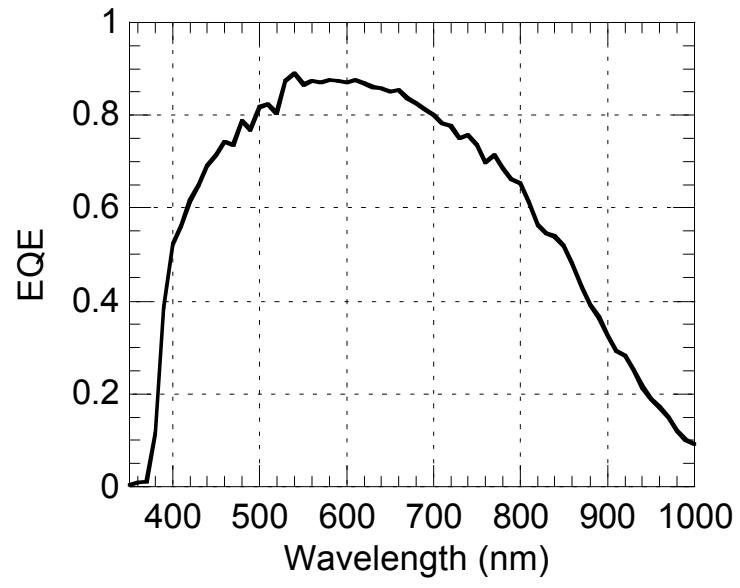

b)

Fig. 3. a) IV curve of optimized $\mu \mathrm{C}-\mathrm{Si}: \mathrm{H}$ solar cell on LPCVD ZnO with 60' of surface treatment. b) EQE of the same cell as in a).

In Fig. 3 the IV and EQE curves of the best cell deposited on front $\mathrm{ZnO}$ optimized for $\mu \mathrm{C}-\mathrm{Si}: \mathrm{H}$ growth with 60 ' of surface treatment, are represented. This cell was obtained after slight re-optimization of the deposition parameters on the new type of substrate. The optimization 
consisted mainly in adjusting the gradient of silane concentration (i.e. the flux of silane divided by the total gas flux) used during the deposition of the intrinsic layer.

The surface treatment applied to $\mathrm{ZnO}$ front TCO for micromorph tandem cells increased the $\mathrm{V}_{\text {oc }}$ from $1.32 \mathrm{~V}$ (no treatment) to $1.41 \mathrm{~V}$ (after 30 ' of surface treatment). A matched solar cell with $12.8 \mathrm{~mA} / \mathrm{cm}^{2}$ was obtained on LPCVD ZnO with 10' of surface treatment. FF and $\mathrm{V}_{\mathrm{oc}}$ were $70.2 \%$ and $1315 \mathrm{mV}$, leading to an initial efficiency of $11.8 \%$ (see also [7]).

\section{DISCUSSION}

\section{Growth of $\mu \mathrm{c}-\mathrm{Si}: \mathrm{H}$ layers on "new" substrate mor- phology}

The new surface morphology of front ZnO TCO presented here highly improves the electrical parameters of the $\mu \mathrm{c}-\mathrm{Si}: \mathrm{H}$ subsequently grown on it. The two main changes of the surface morphology after the treatment are the following:

- absence of small asperities in-between the large surface objects,

- U-shaped valleys instead of the typical V-shaped valleys of the standard $\mathrm{ZnO}$, as optimized for amorphous cells.

Cracks and voids have often been observed in $\mu \mathrm{c}-$ Si:H solar cells grown on LP-CVD ZnO [8]. These cracks usually arise from the tip of the $V$-shaped valleys within the intrinsic layer. A first investigation by transmission electron microscopy (TEM) on samples similar to the ones presented here with 80' of treatment showed that cracks and voids are no more observed when the valleys have a U-shape, i.e. after the treatment. The TEM sample was, however, not optimally thin; the absence of cracks is therefore still to be confirmed by further TEM investigations. We suppose that the absence of cracks during the subsequent deposition of the $\mu \mathrm{c}-\mathrm{Si} \mathrm{H}$ layers may be caused by the TCO surface having, depending on its surface morphology, a different shading effect on the impinging silicon precursors.

\section{Electrical characteristics and surface treatment time}

The surface treatment highly improves the electrical characteristics of the cells for durations below 40 minutes. Further transmission electron microscopy (TEM) investigations should help us to be more affirmative about the hypothesis that the removal of cracks and voids is responsible for the improved values of FF and $V_{\text {oc }}$.

Above 40' of surface treatment, $V_{o c}$ and FF continue to increase, whereas $I_{\text {sc }}$ decreases in the same way. The result is that from 60' to 140' of treatment, $\eta$ remains almost constant at approximately $9.2 \%$.

The decrease of $I_{\mathrm{sc}}$ is caused by smoothening of the surface roughness due to the treatment.

\section{Surface treatment time}

The optimal surface treatment time is, at the moment 60 , as FF and $V_{\text {oc }}$ have for that treatment time already reached high enough values and $I_{s c}$ has not yet started to decrease. Such a long process time is certainly not optimal for the purpose of mass-production. The authors are however confident that with adaptation of the surface treatment process, a reduction of the processing time by a factor 10 is possible, leading to durations compatible with industrial implementation.

\section{CONCLUSIONS}

We have demonstrated here that LPCVD $\mathrm{ZnO}$ is perfectly suited for the fabrication of high efficiency $\mu \mathrm{c}-\mathrm{Si}: \mathrm{H}$ single junction solar cells, thanks, mainly, to the use of a novel surface treatment technique. The versatility of the LPCVD technique for the deposition of the TCO helped us to tune the front TCO properties to the requirements of $\mu \mathrm{C}$ $\mathrm{Si} \mathrm{H}$ solar cells by lowering the doping concentration and increasing the layer thickness. The best $\mu \mathrm{c}-\mathrm{Si}: \mathrm{H}$ solar cell obtained so far on this new kind of front TCO reached $\mathrm{FF}=74.1 \%, \mathrm{~V}_{\mathrm{oc}}=545 \mathrm{mV}$ and $\mathrm{I}_{\mathrm{sc}}=24.7 \mathrm{~mA} / \mathrm{cm}^{2}$, leading to $\eta=9.9 \%$. This efficiency is the highest ever reported for cells deposited on front ZnO deposited by LPCVD and it compares very well with the best results of other groups on sputtered and etched $\mathrm{ZnO}$.

The reason for such an improvement is to be found in the change of the surface morphology of the front TCO. Apparently, the surface is slightly smoothened by the treatment and small asperities are erased. The typical Vshaped valleys of the LPCVD $\mathrm{ZnO}$ are replaced by $\mathrm{U}$ shaped valleys that are apparently best suited for the subsequent growth of $\mu \mathrm{c}-\mathrm{Si}: \mathrm{H}$ single junction solar cells.

\section{ACKNOWLEDGEMENTS}

The authors gratefully acknowledge support by the Swiss Federal Energy Office (OFEN) under grant number 101191.

\section{REFERENCES}

[1] Meier, J., et al., Thin Solid Films, Vol. 451-452 (2004) 518.

[2] Nasuno, Y., et al., Solar Energy Materials and Solar Cells, Vol. 74 (2002) 497.

[3] Mai, Y., et al., Journal of Applied Physics, Vol. 97

(2005) 114913.

[4] Rech, B., et al., Thin Solid Films, Vol. (2005)

[5] Steinhauser, J., et al., Proc. of the 20th EU PVSEC, 2005, 1608

[6] Feitknecht, L., et al., Technical digest of the 15th International PV SEC, Shangai, Vol. 1 (2005) 473.

[7] Dominé, D., et al., this conference

[8] Bailat, J., et al., Journal of Non-Crystalline Solids, Vol. 299-302 (2002) 1219. 